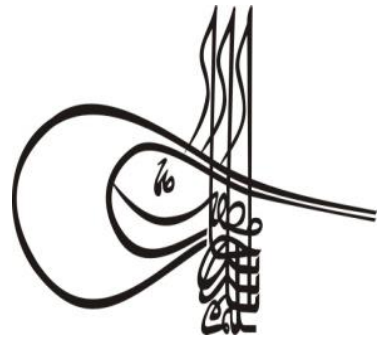

Received/Geliş: 03.02.2019
Turkigl Studies

Economics, Finance, Politics

Volume 14 Issue 2, 2019, p. 407-421

DOI: 10.29228/TurkishStudies. 22643

ISSN: 2667-5625

Skopje/MACEDONIA-Ankara/TURKEY

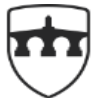

INTERNATIONAL BALKAN UNIVERSITY

EXCELLENCE FOR THE FUTURE IBU.EDU.MK

Research Article / Araştırma Makalesi

Article Info/Makale Bilgisi

VAccepted/Kabul: 10.06 .2019

Gor Report Dates/Rapor Tarihleri: Referee 1 (24.02.2019)- Referee 2 (10.03.2019)

This article was checked by iThenticate.

\title{
KARADENİZ EKONOMİK İŞBİRLİĞİ KAPSAMINDA TURİZM SEKTÖRÜNE YÖNELİK YAPILAN ÇALIŞMALARIN INNCELENMESI
}

\author{
İsmail KIZILIRMAK* - Suna MUGAN ERTUGRAL** \\ Sezgi GEDIK ${ }^{* * *}$ - Hacer Neyir TEKELI' $\dot{I}^{* * *}$
}

\begin{abstract}
öz
Küreselleşme ile birlikte ülkeler arasındaki ticari ve sosyal ilişkilerin değişim göstermesi, rekabetin artması, ülkeleri yeni güç dengeleri oluşturmaya yöneltmiştir. Bu durum özellikle komşu sınırları olan, benzer kültürel ve sosyal değerlere sahip ülkelerin bir araya gelmesini sağlamıştır. Bu doğrultuda Karadeniz Ekonomik İşbirliği (KEİ) gibi uluslararası örgütler oluşmuş, yeni, güçlü işbirlikleri kurulmuştur. Coğrafi yakınlık ve sosyal ilişkiler ticari hareketlere de yansımış ortak amaçlar, ortak hedefleri beraberinde getirmiştir.

1980'lerin sonuna gelindiğinde Doğu Avrupa Ülkeleri ve Sovyetler Birliği'nde başlayan değişim süreci hız kazanmıştır. $\mathrm{Bu}$ süreç, Türkiye'nin de içinde bulunduğu, Karadeniz'e kıyısı olan ülkeleri bir araya getirmiş ve bölgesel bir bütünleşme sağlama amacıyla Karadeniz Ekonomik İşbirliği (KEİ) düşüncesinin ortaya çıkmasına sebep olmuştur. Bu düşünce, 1992 yılında on bir ülkenin katılımıyla hayata geçirilmiştir. Böylece Karadeniz Bölgesine yönelik ticari ve sosyal işbirlikleri güç kazanmıştır.
\end{abstract}

KEİ kapsamında bir araya gelen üye ülkeler arasında gerçekleşen ticari ve kültürel işbirlikleri, turizmin de gelişmesinde rol oynamıştır. Diğer taraftan turizm, üye ülkeler arasında sıcak ilişkiler kurulmasına

Prof. Dr., İstanbul Üniversitesi İktisat Fakültesi, E-posta: ikizilirmak@istanbul.edu.tr

Dr. Öğr. Üyesi, İstanbul Üniversitesi İktisat Fakültesi, E-posta: sertugral@ yahoo.com

Dr., İstanbul Üniversitesi, E-posta: sgedik@istanbul.edu.tr

Dr. Öğr. Üyesi, İstanbul Kültür Üniversitesi, E-posta: n.tekeli@iku.edu.tr 
yardımcı olmaktadır. Bununla birlikte Karadeniz Bölgesi, tarım, enerji, doğal kaynaklar, doğal fiziksel özellikler ve kültürel değerler bakımından son derece zengin kaynaklara sahip olduğundan bölgede turizm hızlı bir şekilde gelişme göstermektedir. Turizmin bölgede gelişimi, bölgesel kalkınmanın sağlanması açısından da önemlidir.

Yapılan bu çalışma ile KEİ'nin Karadeniz Bölgesinde turizmin gelişimine olan katkısını ortaya çıkarmak amaçlanmıştır. Çalışmanın istenilen amaçlarına ulaşabilmek için literatür taraması yapılmış ve KEİ'nin kurulduğu zamandan itibaren yapmış olduğu toplantılar incelenmiş, turizme yönelik alınan kararlar, uygulamalar ve geleceğe dönük hedefler başlıklar altında sunulmuştur ve değerlendirilmiştir. Türkiye

Anahtar Kelimeler: Karadeniz Ekonomik İşbirliği, Turizm,

\title{
INVESTIGETION OF THE STUDIES RELATED TO THE TOURISM SEKTOR UNDER THE BLACK SEA ECONOMIC COOPERATION
}

\begin{abstract}
Together with globalization, trade and social relations between countries have changed, competition has increased, and countries have directed new power balances. This situation has brought together countries with similar cultural and social values, especially with neighboring borders. In this context, international organizations such as the Black Sea Economic Cooperation (BSEC) have been formed and new strong partnerships have been established. Geographical proximity and social relations are also reflected in commercial movements and have brought common goals.

In the 1980s, the process of change in the Eastern European countries and the Soviet Union accelerated. This process, in which Turkey has also been found, brought together the countries bordering the Black Sea and creating a favorable environment for regional integration initiatives of the Black Sea Economic Cooperation (BSEC) has led to the emergence of the idea. This idea was realized in 1992 with the participation of eleven countries. Thus, commercial and social cooperation towards the Black Sea Region gained strength.
\end{abstract}

The commercial and cultural collaborations that took place among the member countries that came together under the BSEC played a role in the development of tourism. On the other hand, tourism helps to establish warm relations among the member countries. However, since the Black Sea region has extremely rich resources in terms of agriculture, energy, natural resources, natural physical properties and cultural values, tourism in the region is developing rapidly. The development of tourism in the region is also important in terms of ensuring regional development.

This study aims to reveal the contribution of the BSEC to the development of tourism in the Black Sea Region. In order to reach the desired objectives of the study, literature review was conducted and the

Turkish Studies - Economics, Finance, Politics

Volume 14 Issue 2, 2019 
meetings of the BSEC since its establishment were examined, the decisions taken for tourism, practices and future targets were presented and evaluated under the headings.

\section{STRUCTURED ABSTRACT}

Globalization, which is effective in every field of life, has also brought about changes in national and international organizational structures. Now, the power of communication technology is increasing the speed and prevalence of social interaction on the world. These processes, which are intertwined with economic, political and cultural dimensions and affected by the elements of change, affect the global society. This development reveals new social structures at the global level and changes existing social structures.

Especially, the wars and political regime changes experienced in the countries adjacent to the Black Sea caused negative consequences for economic growth in the Caucasus and the Balkans. This situation is causes interregional development differences. Therefore, the economic development of countries is also important in terms of creating peace and prosperity in the countries of the region. The development of international mutual trade will accelerate investments and ensure economic development. The expansion of international trade and investments will also increase economic growth. It is important that Turkish investors turn to the region. This orientation was the result of the democratization efforts of these countries with a relatively closed economy. Political environments in countries have important effects on investors' decisions ere (Uray, 2008: 25). For this reason, regional cooperation is important.

With the founding of the United Nations in 1945, the basic factor determining international relations was the idea of states. Nowadays, new factors have emerged which affect the international relations and the world economy more than the states. These factors play a significant role in international relations. At the same time, these factors are important as the mechanism of power. Because of the World War II, international organizations have become more and more important. These organizations show the factor that is constantly affecting development in the process of globalization. International organizations are among the most active and dynamic elements of the World system. The number of these organizations, whether inter-state or non-governmental, is increasing rapidly. These institutions, which have existed since the $1945 \mathrm{~s}$, have increased their spheres and powers in the process of globalization. As the globalization process progresses, the international organization will increase.

The Government of Turkey, unadventurous in foreign policy since its inception and has followed a strategy to avoid endangering the country's security. The establishment of peace in the regional and global sense has been important. In this context, contributing to the development of inter-state relations has been one of the policy priorities (Kiraz, 2018: 128). These priorities within the scope of Turkey is also actively involved with the aim of establishing the BSEC countries bordering the Black Sea between stage as a "free trade zone" is determined to be founded. However, at the later meetings it was stated

Turkish Studies - Economics, Finance, Politics

Volume 14 Issue 2, 2019 
that this initiative should be evaluated within the framework of "economic cooperation". The BSEC aims to diversify and further develop bilateral and multilateral economic, technological and social relations between the potentials of their member countries, their geographical proximity and their complementary nature, thereby making the Black Sea basin a peace, stability and prosperity region. The vehicle chosen to achieve this objective is economic cooperation (http://www.eecon.info/papers/661.pdf). The economic cooperation within the Black Sea between Turkey and neighboring countries agreements and joint investments in different sectors has led to an increase in trade relations. These agreements have led to the development of economic integration among the countries in the region. Economic development in the region will provide more favorable and favorable conditions for commercial activities. Developments in this direction have accelerated the mutual foreign trade. The issue of economic development of countries is very important in this evaluation.

This study aims to reveal the contribution of the BSEC to the development of tourism in the Black Sea Region. In order to reach the desired aims of the study, literature review was done. The meetings of the BSEC since its establishment were examined. The decisions, practices and future targets for tourism are presented and evaluated under the headings. Economic collaborations are intended to improve economic, commercial, cultural and political relations and contribute to participation. At the same time, they make a significant contribution to the preservation of environmental protection and conservation of cultural values. The cooperation to be established in this direction will be important in terms of increasing tourism revenues, number of tourists and average expenditures. The protection of the natural environment and cultural values of the region is extremely important in terms of ensuring sustainable tourism. Inter-country cooperation also contributes to the protection and improvement of regional values. In this context, mutual arrangements are important. In this study, the BSEC, which is in our study area, is an important movement in this regard. The BSEC is very important in terms of ensuring regional development and developing commercial relations.

The BSEC market can easily reach Europe, Central Asia and the Middle East regions geographically. This market is in a position to have a say in the markets there. The Black Sea is the fourth largest inland water on earth. The Black Sea is the fourth largest inland water on earth. For this reason, Black Sea has economic opportunities in terms of sea transportation. In addition, Black Sea has an important source of richness in terms of sea tourism. In this respect, tourism is also included in sectoral cooperation. Tourism in this respect is important in the Black Sea Region. In order to improve tourism in the BSEC region;

- To promote the BSEC region as one of the leading tourism destinations,

- Facilitating visa procedures, strengthening the cooperation of member states in the field of tourism,

- To ensure the development of sustainable tourism,

- Promote new tourism packages in the BSEC region,

Turkish Studies - Economics, Finance, Politics

Volume 14 Issue 2, 2019 
- To conduct joint marketing activities between the BSEC members and other countries,

- Establish a network between tourism professionals, travel agencies and associations of Member States,

- To develop joint projects in the fields of maritime, winter sports, health, SPA, Wellness and business tourism,

- To promote cultural tourism / culture path projects in the Black Sea region,

- To increase internship opportunities of students in BSEC member states, there is a web portal for graduates who want to continue their careers in the tourism and hospitality sectors.

BSEC is very important for the rapid development of economic activities among the neighboring countries of the Black Sea. Black Sea Region countries have rich resources in terms of agriculture, energy, natural resources, natural physical properties and cultural values. The contribution of tourism to regional development is extremely important in the areas determined to improve cooperation between countries in the region. Especially the natural physical characteristics and cultural values of the region allow the development of the tourism sector. The development of tourism in the countries of the region is important in ensuring regional development. In particular, the diversification of tourism, the protection of the environment and the adoption of sustainable tourism allow the conservation of environment and cultural values in the region and the diversification of tourism. In addition, the provision of tourism education in the region effectively and increasing the quality of service in the facilities ensures the development of qualified workforce and qualified facilities. At the same time, tourism planning can strengthen the regional economy. Prioritization of promotional activities in the BSEC Member States will increase the tourist demand. The studies that will contribute to this development have been dealt with by joint studies and collaborations between the member countries. Working groups in this regard have followed a sensitive attitude. It is imperative to develop works and protocols in the provision of regional development.

Turkey.

Keywords: The Black Sea Economic Cooperation, Tourism,

\section{Giriş}

Hayatın her alanında etkili olan küreselleşme, ulusal ve uluslararası örgüt yapılarında da değişimleri beraberinde getirmiştir. Günümüzdeki iletişim teknolojisinin gücü dünya üzerinde toplumsal etkileşimin hızını ve yaygınlığını giderek arttırmaktadır. Ekonomik, siyasal ve kültürel boyutların iç içe geçmesi ve bireylerin dünyanın neresinde olursa olsun bu değişim öğelerinden etkilenişleriyle yaşanan bu süreçler küresel toplumu ve küresel düzeyde yeni toplumsal yapıları ortaya çıkarmakta ayrıca mevcut toplumsal yapıları da değişikliklere uğratmaktadır.

Özellikle Kafkasya ve Balkanlarda Karadeniz'e komşu ülkelerde bu süreçte yaşanılan savaşlar ve siyasi rejim değişiklikleri iktisadi büyüme açısından olumsuz sonuçlar doğurmuştur. Bu durum ise, bölgelerarası gelişmişlik farklılıklarına sebep olmaktadır. Dolayısıyla ülkelerin ekonomik bakımdan gelişmeleri bölge ülkelerinde huzur ve refah ortamının oluşması açısından da önemlidir. Ülkelerarası 
karşılıklı ticaretin gelişmesi yatırımları hızlandırarak ekonomik kalkınmayı sağlayacaktır. Uluslararası ticaretin ve yatırımların genişlemesi de ekonomik büyümeyi arttıracaktır. Türk yatırımcıların bölgeye yönelmeleri nispeten kapalı ekonomiye sahip bu ülkelerin demokratikleşme çabalarının sonucunda gerçekleşmiştir. Özellikle "ülkelerdeki siyasal ortamlar yatırımcıların kararları üzerinde önemli etkilere sahiptir” (Uray, 2008:25). Bu sebeple bölgesel işbirlikleri önemli olmaktadır.

1945 'te Birleşmiş Milletler 'in de kurulması ile birlikte uluslararası ilişkileri belirleyen temel faktörün devletler olduğu düşünce esasken artık günümüzde uluslararası ilişkileri ve dünya ekonomisini devletlerden daha çok etkileyen yeni faktörler ortaya çıkmıştır. Bu faktörler, uluslararası ilişkilerde ciddi bir rol oynayan, ulusal ve uluslararası platformlarda sosyal, ekonomik, politik konularda söz hakkı olan hatta karar alabilen, bu kararları uygulatan güç mekanizması olarak uluslararası örgütlerin varlığı ve konumu tartışılmazdır. II. Dünya Savaşı sonrasında giderek güçlenen ve sayıları artan uluslararası örgütlerin varlığı, küreselleşme sürecinde bu belirleyici ve gelişime sürekli etki eden faktörün ne ş̧ekilde yer aldığını gözler önüne sermektedir. Dünya sisteminin en aktif ve dinamik öğelerinden olan uluslararası örgütler ister devletlerarası olsun ister hükümetler dışı olsun sayıları hızla artmaktadır. 1945'lerden beri var olan, ülkeler arası ilişkileri düzenleyen bu kurumlar küreselleşme sürecinde etki alanlarını ve güçlerini arttırmışlardır. Küreselleşme süreci ilerledikçe uluslararası örgütleşme de artacaktır.

Türkiye kuruluşundan itibaren dış politikasında maceracı olmayan ve ülkenin güvenliğini tehlikeye atmaktan kaçınan bir strateji izlemiştir. Bunun yerine genellikle bölgesel ve küresel anlamda barışın tesis edilmesi ile diplomasi ve diyalog kanallarının açık tutulması suretiyle devletlerarası ilişkilerin gelişmesine katkı sağlamak politika önceliklerinden olmuştur (Kiraz, 2018:128). Bu öncelikler kapsamında KEİ'nin ilk amacı Karadeniz'e kıyısı bulunan, Türkiye'nin de aktif olarak içinde yer aldığı, ülkeler arasında "serbest ticaret bölgesi" oluşturmak olarak belirlenmiş fakat yapılan toplantılarda "ekonomik işbirliği" oluşturulması amacı öne çıkmıştır. Bu amaç ile KEİ üye ülkelerinin, coğrafi yakınlıklarından ve benzer sosyo-kültürel ögelerinden yararlanarak, ticari ve sosyal ilişkilerin geliştirilmesi, tamamlayıcı nitelikte çoklu ilişkilerin kurulması böylece bölgede istikrar ve refahın devamlılı̆ının sağlanması amaçlanmaktadır. (http://www.eecon.info/papers/661.pdf; http://disiliskiler.kulturturizm.gov.tr). Türkiye'nin de içinde bulunduğu Karadeniz'e kıyısı olan ülkeler arasında gerçekleştirilen, ekonomik işbirliği anlaşmaları ve farklı sektörlerde yapılan ortak yatırımlar, ticari ilişkilerin artmasına sebep olarak bölge ülkeleri arasında ekonomik entegrasyonun gelişmesine sebep olmuştur. Bölgede ekonomik gelişme olduğu sürece ticari faaliyetlerde daha olumlu ve uygun koşulların oluşması beklenmelidir. $\mathrm{Bu}$ doğrultuda oluşan gelişmeler karşılıklı diş ticareti hızlandırmıştır. Ülkelerin ekonomik gelişmişlikleri konusu ise bu değerlendirmede oldukça önemlidir.

\section{Karadeniz Ekonomik İşbirliği}

Ekonomik ve ticari amaçlı kurulan bölgesel birlikler, bölgesel olarak uzmanlaşma, kendi içinde ticari ilişkilerini geliştirme, yabancı sermayeyi bölgeye çekme, birlik dışında kalan ülkelere karşı ticaret politikası geliştirme, ekonomik büyümeyi hızlandırma gibi amaçlarla kurulmaktadır (Gürlesel ve Demir, 2002:91). Bu sebeple bölgesel işbirlikleri, karşılıklı ticari ve kültürel ilişkilerin geliştirilmesi açısından önem taşımaktadır.

Karadeniz'e komşu ülkelerin, coğrafi yakınlıkları ve siyasi sistem değişikliği sonrası yeni gelişen ekonomik ilişkileri sebebiyle aralarındaki iktisadi, ticari, kültürel, teknik ve bilimsel ilişkileri geliştirme ve işbirliği çerçevesinde bütünleşme ihtiyacı doğmuştur. $\mathrm{Bu}$ ihtiyaçtan yola çıkılarak Türkiye'nin de içinde bulunduğu, Karadeniz'e kıyısı olan on bir ülkenin katılı ile KEİ kurulmuştur (http://www.mfa.gov.tr). 2019 itibari ile KEİ'nin 12 üye ülkesi (Sirbistan katılımı ile) bulunmakta olup Amerika Birleşik Devletleri ve Avrupa Birliği Komisyonu ile 11 ülke, örgüt bünyesinde gözlemci olarak yer almaktadır(https://ab.ticaret.gov.tr). 
Türkiye'nin kurucu üyesi olduğu KEİ, bölgesel bir ekonomik işbirliği örgütüdür. Örgütün başta ticari ilişkiler ve ekonomik kalkınma konuları olmak üzere diğer işbirliği konuları enerji, teknoloji, sağlık, turizm, haberleşme, finans, ulaştırma, çevre vb. konulardır (www.kosgeb.gov.tr).

\section{Karadeniz Ekonomik İşbirliği Kapsamında Turizm}

Küreselleşme ile birlikte, coğrafi yakınlık ve/veya ortak sosyo-kültürel değerlere sahip ülkelerin bir araya gelmesi ile kurulan örgütler, uluslararası nitelikteki konularda kararları etkileyebilecek önemli oluşumlar arasında yer almaktadır. STK'ların sayılarının ve gücünün artması, uluslararası sınırların küreselleşme ve teknolojik gelişimler ile ortadan kalkması ve sosyo-ekonomik değişimler örgütlerin de turizm gibi uluslararası konulara olan ilgisini artırmıştır (Dinçer vd., 2015:1112). Turizm, ekonomik ve sosyal getirilerinin yanı sıra sıcak ilişkilerin de kurulmasında rol oynayan çok boyutlu bir sektördür.

Uluslararası örgütlerin doğrudan turizm üzerine temel çalışma politikaları olduğu gibi turizm dünyasını yakından etkileyecek turizm bağlantılı uygulamaları ve kararları da vardır. Turizm hareketlerine etki eden temel çalışmalar; turizmin olumlu düzeydeki ekonomik, sosyal, kültürel etkilerini en üst düzeylere çıkarılması, kültürel mirasın korunması, bunlarla birlikte sosyal ve çevresel zararları da en alt düzeye indirmeyi sağlayacak özel önlemlerin alınması doğrultusunda sorumlu, sürdürülebilir bir turizm kalkınmasının geliştirilmesidir.

KEİ üyesi ülkeler arasında işbirliği yapılacak olan sektörlerin başında, turizm sektörü gelmiş ve bu amaca yönelik bugüne kadar kamu ve özel sektör kuruluşlarınca birçok çalışma yapılmıştır. Bu çalışmalar arasında; seyahatlerde başta vize olmak üzere sınır formalitelerinin azaltılması, turizm sektörünün geliştirilmesine yönelik ortak projelerin yapılması ilk akla gelenlerdir. Yine üye ülkelerce, kruvaziyer turizmi başta olmak üzere turizm çeşitlerinin geliştirilmesi, bölgeye yönelik ortak tur programlarının oluşturulması ve turizm amaçlı tanıtım ve pazarlama stratejilerinin geliştirilmesi de üye ülkelere yönelik turizm hareketlerinin gelişmesi için yapılan diğer uygulamalardır.

Karadeniz ülkeleri arasında turizm işbirliği, bölgedeki doğal zenginliğin ve bol mirasının tanıtılması için yöntemler aranmasına dayanan KEİ'nin faaliyet şekilleri aşağıdaki şekilde sıralanabilir (http://www.bsec-organization.org);

- Zengin potansiyelin tanıtımına yönelik teşvikler,

- Üye devletlerarasındaki aktivitelere gerekli araç oluşturacak ortak programlar ve projeler,

- Turizm potansiyelinin tanıtımına yönelik kurumsallaşmış organları oluşturmak,

- Karadeniz Ekonomik İşbirliği’ndeki turizm aktivitelerini özel sektörle bir araya getirmek,

- Bir web sitesi kurarak bölgedeki veya daha geniş ölçekteki fuarlara karşılıklı katılımı teşvik etmek ve turistik bulguları geliştirmek,

- Turizm destinasyonu olarak Karadeniz bölgesinden ortak bir marka yaratmak.

\section{Karadeniz Ekonomik İşbirliği’nin Turizm Sektörüne Yönelik Aldığı Kararlar}

KEİ, kurulduğu günden itibaren çok sayıda toplantı yapmış ve yeni kararlar almıştır. $\mathrm{Bu}$ doğrultuda KEİ'nin turizme yönelik almış olduğu kararlar aşağıdaki şekilde özetlenebilir. ${ }^{1}$

\footnotetext{
${ }^{1}$ KEİ toplantılarında alınan kararlardan derlenmiştir.
} 


\subsection{KEİ Bölgesinde Geliştirilmesi Düşünülen Turizm Türleri}

Karadeniz Bölgesinin coğrafi özellikleri, doğal ve kültürel unsurları bölgede turizmin gelişmesi, çeşitlenmesi açısından oldukça zengin bir kaynak sağlamaktadır. Bölgeye yönelik ziyaretler iş amaçlı ticari faaliyetlerin ötesine geçmelidir. $\mathrm{Bu}$ anlamda doğal ve kültürel faktörleri değerlendirmek son derece önemlidir. Bu kapsamda KEİ bölgesine yönelik geliştirilmesi planlanan turizm çeşitleri ve bu amaçla yapılan toplantılara yönelik bilgiler aşağıdaki gibidir;

Kültür Turizmi; Kültür turizmi, sağladığı sosyo-kültürel ve ekonomik kazanımlarından faydalanan toplumlar sahip oldukları kültürel değerleri de daha fazla koruma ve kullanma eylemi içerisine girmektedir (Koca vd., 2018:943). Kültür turizmi, bölgede geliştirilmesi öncelikle düşünülen turizm türlerinin başında gelmektedir. Konu ile ilgili olarak ilk çalışmalar 2006 yllında, efsanevi "Argo" gemisinin yeniden inşası çalışmasının başlatılması ve bu gemi ile 50 AB temsilcisinin katılımıyla Argonatların tarihi güzergahından Karadeniz’in Doğu kıyılarına uzanacak bir keşif gezisinin planlamasına yönelik bir kültür projesinin hazırlanması ile başlatılmıştır (Bükreş, 2006).

2009 yılında yapılan toplantıda ise, Türkiye tarafindan hazırlanan İpek Yolu'nun Sapanca Koridoru, AYAŞ, Örnek Çalışmaları ve Avrupa Konseyi tarafından hazırlanan "Şarap Kültür Turizmi Değişim Projesi ”ne KEİ’nin katılımına ilişkin önerilerde bulunulmuştur (İstanbul, 2009).

2010 yılında yapılan Turizm Çalışma Grubu toplantısında da, kültür turizmin geliştirilmesine yönelik olarak somut proje örnekleri belirlenmiş ve üye devletlerin proje ortaklıkları konusu görüşülmüştür. Söz konusu Kültürel Turizm Planı ile ilgili üye ülkelerce hazırlanan projeler şunlardır;

- Sikke Güzergahları (Yunanistan),

- Roma İmparatorluğu Kültür Yolları (Sırbistan),

- İpek Yolu Projesine (Türkiye),

- Azerbaycan Şarap Güzergahları (Azerbaycan),

- Ermenistan Bağ ve Şarap Güzergahları (Ermenistan),

- Argonautların Efsanesi (Gürcistan).

Yukarıda yer alan projelerin yanında Türkiye ile KEIPA (Karadeniz Ekonomik İşbirliği Parlamenter Asamblesi) işbirliği kapsamında Zeytin Ağacı Yolu, Viking Yolları, Fenikeliler Yolu projeleri de bulunmaktadır. Bu projeler ile kültürlerarası paylaşımların devam etmesi, bölgelerde bulunan somut kültürel mirasın korunması, restorasyonunun yapılması, Kafkasya-Anadolu-Avrupa güzergahında kültür turizmine yönelik yeni rotaların oluşturulması ve kültür turizmi vesilesiyle yeni istihdam imkanlarının geliştirilmesi amaçlanmaktadır (www.pabsec.org).

Turizm Çalışma Grubu toplantılarında söz konusu projelerin gerçekleştirilerek hayata geçirilebilmesi için finansal desteklerin bulunması ve projelerin başlatılmalarına yönelik gerekenlerde tartışılmıştır. Bu amaçla oluşturulan ortak Çalışma Grubu, her bir proje sahibi ülkenin birbiriyle ya da ortaklarıyla gerek internet üzerinden gerekse de düzenlenecek olan workshoplarda bir araya gelerek bilgi alış verişinde bulunmasını, sonuçları tartışmasını kısacası işbirliği içinde olmalarını kararlaştırmıştır. Ayrıca Ortak Çalışma Grubu, projelerin yönetilmesi ve başarılı olabilmesi için KEİ Proje Geliştirme Fonunu da, proje çalışmalarına destek verilmesini önermiştir. Ayrıca Türkiye tarafından yürütülmekte olan İpek Yolu" projesine, KEİ İş Konseyi Genel Sekreterliği tarafindan yürütülmesinde özel sektörle işbirliği içerisinde bulunulması gerektiğine de karar verilmiştir (İstanbul, 2010). Son olarak gerçekleşen 8. Uluslararası İpek Yolu Turizm Toplantısı'nda "Küreselleşmiş bir turizm çerçevesindeki İpek Yolu: turizm öncelikleri, bölgesel kalkınma planları ve tarihi yolların rolü" başl1klı ana tema üzerine görüş alışverişinde bulunulmuştur (Selanik, 2018). 
Karadeniz Bölgesinin çok kültürlü bir karaktere sahip olması nedeniyle, KEİ’ye üye devletler tarafından yeni bir turizm konsepti olarak bölgenin geliştirilmesi teklifinde bulunulmuş (Yalta, 2013) ve Evliya Çelebi (Kültür Yolu) teklifi de Türkiye tarafından önerilmiştir (İstanbul, 2014). Planlanan ve hayata geçirilen projeler incelendiğinde, KEİ bölgesi kültür turizmi açısından zengin bir potansiyele sahiptir.

İçinde Türkiye'nin de bulunduğu Sınır Ötesi Düzeyde Miras Turizmi için Kalite Standartlarını geliştirmek amaciyla yedi KEİ Üye Devlet (Bulgaristan Cumhuriyeti, Gürcistan, Helen Cumhuriyeti, Moldova Cumhuriyeti, Romanya, Türkiye Cumhuriyeti ve Ukrayna) tarafindan uygulanan Çok Düzeyli Aktörlerin Ortak Ağları Projesi sunum aşamasına gelmiştir (Burgaz, 2017).

Birleşmiş Milletler Dünya Turizm Örgütü (UNWTO) - Birleşmiş Milletler Eğitim, Bilim ve Kültür Kurumu (UNESCO) işbirliğiyle düzenlenen "Sürdürülebilir ve yaratıcı şehirler için kültürel turizm", "Somut olmayan kültürel mirasın korunmasında bir müttefik olarak sorumlu turizm" ve "Dijital dönüşüm yoluyla herkes için kültür turizminin sağlanması" konularını ele alan 3. Dünya Turizm ve Kültür Konferansına katılan KEİ kültür turizmine yönelik ilgisini de ortaya koymuştur (İstanbul, 2018).

Deniz Turizmi; Karadeniz bölgesinin dünyanın en önemli dördüncü iç su olmasından dolayı deniz ve nehirler açısından sahip olduğu potansiyel kruvaziyer turizminin yanı sıra deniz turizminin geliştirilmesine yönelik avantajlı konuma getirmektedir. Konu ile ilgili olarak 2002, 2005, 2007 ve 2010 yıllarında yapılan toplantılarda kruvaziyer ve deniz turizmi ile ilgili çeşitli konular ele alınmıştır. $\mathrm{Bu}$ amaçla ilk olarak Karadeniz Kurvaziyer birliği kurulması ile ilgili önerinin araştırılması, KEİ bölgesinde denizcilik ve deniz turizminde ortak ilkelere ulaşmak amaciyla üye devletler, kendi ülkelerindeki turist limanlarının yasal çerçevesi, hizmet kalitesi, çevre sorunları, promosyon konuları ile ilgili bir taslak hazırlanmasının gerekliliği kararlaştırılmıştır (Belgrad, 2007).

KEİ bölgesi için önemli olan denizcilik ve deniz turizmi ile ilgili olarak üye devletler arasında işbirliğinin sağlanması ve turizm amaçlı kullanılan limanların çeşitli kategorileri için ortak bir terminoloji oluşturmak amaciyla, KEİ Turizmde İşbirliği Çalışma Grubuna denizcilik ile ilgili yasal düzenlemelerin derlenip toplanması önerilmiştir. Bu kapsamda Çalışma Grubu, kültürel değişimlerde, deniz fuarlarında, yat yarışlarında, deniz rotalarında ortaklığı teşvik etmek amacıyla KEI üye devletlerin bir deniz ağı kurmalarını kolaylaştıracak çalışmaları da başlatmaya karar vermiştir.

2010 yılında Atina'da yapılan toplantıda da yat ve kruvaziyer turizmini içine alan deniz turizmi, KEİ bölgesinde turizmin geliştirilmesinde önemli bir araç olarak değerlendirilerek uluslararası anlaşmalar ve yönetmelikler çerçevesinde rekabet edilebilirliği sağlanmasının önemi vurgulanmıştır (Atina, 2010).

UNWTO ve Kültür ve Turizm Bakanlığı tarafından "Karadeniz ve Doğu Akdeniz'de Kruvaziyer Turizmi Çekme Konferansı"nın 2019 yılı bahar döneminde için İstanbul'da organize edilmesi için planlama yapılmıştır (Varna, 2018). 2018 yılında gerçekleşen konferans da yine Türkiye'de gerçekleşmiştir.

Özel İlgi Turizmi; Karadeniz bölgesi özel ilgi türleri açısından da oldukça önemli kaynaklara sahiptir. Bu amaçla geliştirilebilecek olan turizm türleri arasında eko turizm ilk sırada yer almaktadır. $\mathrm{Bu}$ amaçla KEİ Turizm İşbirliği için eylem planında eko turizm ile ilgili 2006 yllında 4 günlük bir seminer organizasyonu düzenlenmiştir (Rodos, 2005). KEİ bölgesi içinde uygun olan yerlerde, var olan ya da yeni projelerle özellikle belirtilen bölgelerde özel ilgi turizmi alanında işbirliğine teşvik etmeye yönelik çalışmalarda planlanmıştır (Atina, 2010).

Gastronomi ve Şarap Turizmi, Film Kaynaklı Seyahat (Film Turizmi) türleri de özel ilgi turizmi kapsamında geliştirilebilecek olan diğer turizm türleridir. Bu amaçla, üye devletlerin sahip oldukları potansiyeli anlatacak tanıtım malzemelerini hazırlamaları, birbirleriyle işbirliği yapmaları ve 
bu turizm türlerinin geliştirilmesine yönelik somut öneriler getirmeleri de karara bağlanmıştır (İstanbul, 2014).

Kış ve Spor Turizmi; KEİ üyesi devletlerde spor turizmi de geliştirilebilecek olan turizm türleri arasındadır. Bu nedenle kış ve spor turizmi alanında teşviklerin sağlanması önerilmiştir (Atina, 2010).

Termalizm, Wellness ve SPA Turizmi; KEİ bölgesinde geliştirilmesi düşünülen turizm türleri arasında; sağlık, SPA ve Wellness turizmi de bulunmaktadır. Bu turizm türlerine yönelik potansiyele sahip olan ülkelerin bu zenginliklerini birer turizm ürünü haline getirmeleri için gereken teşvikler sağlanmalıdır (Atina, 2010).

İş Turizmi; KEİ üyesi ülkelerde geçmişten özellikle bavul turizmi örneğinde olduğu gibi, ülkelerin ticari hayatlarına büyük destek sağlayan bu turizm türünün daha da geliştirilebilmesi için çeşitli teşviklerin sağlanması gerekmektedir.

Gastronomi ve Şarap Turizmi; Tüketici davranışlarının değişmesi ile karma bir tüketim olgusu ortaya çıkmıştır. Tüketiciler yaşam kalitesini yükseltmek, yaşamına anlam katmak ve daha fazla deneyim kazanmak için kitle turizminden özel ilgi turizmine doğru yönelmektedir. Gastronomi ve şarap turizmi de bu tarz tüketiciler için tercih edilen özel ilgi turizmi çeşitleri arasında yer bulmaktadır (Ergüven, 2015:451). Daha önceki toplantılarda da yer alan bu turizm çeşidi son 5 yıl içinde özel olarak ilgilenilen turizm türleri içinde yer almıştır. Özellikle son yıllarda yükselişte olan gastronomi turizmine yönelik çalışmalarını da yürütmeye başlamış ve ilk olarak Rusya Federasyonu, Madrid'de "Rusya Gastronomi Haftası" pilot projesini yürütmüştür (Türkiye, 2015). 2018 yılında yapılan toplantıda Rusya "Karadeniz Mutfağı - Kalkınma ve Tanıtım Programı" konulu bir sunum yapmiştır.

Film Turizmi; Film turizminin tanıtımına ilişkin bir envanterinin oluşturulması olasıllı̆ı gündeme gelmiştir (Türkiye, 2015). Bu kapsamda Ukrayna'da 9. Odessa Uluslararası Film Festivali 13-21 Temmuz 2018 tarihleri arasında gerçekleşmiştir (Burgaz, 2017).

\subsection{KEİ Bölgesine Yönelik Tanıtım Çalışmaları}

KEİ üye ülkeleri, bölgenin bilinirliğini artırmak ve turizmi geliştirmek amacı ile tanıtıma yönelik bazı kararlar almış, hedefler belirlemiştir. Bu kararlar öncelikle bölgenin sahip olduğu potansiyeli dünyaya göstermek, turizm çeşitliliğini ve turist sayısını arttırmak hedeflerine bağlı olarak gelişmiştir. Aşağıda bu doğrultuda yapıımış çalışmalar maddeler halinde yer almaktadır:

- Pazar hedeflerine ve stratejilerine dayalı uzun dönemlik bir program hazırlamak,

- Turizmi mevsimsel dengesizliklerden kurtararak bağımsızlığını artırmak ve coğrafi dağılımında denge kurabilmek,

- Mevcut Pazar bölümlerinin özel ihtiyaçlarını karşılamak için turizm firsat ve olanaklarını değerlendirmek ve desteklemek,

- Müşteri odaklı medyaya yönelik reklamlar,

- Ortak KEİ standı ile turizm fuarlarına katılmak,

- Profesyonel endüstri için workshoplar organize etmek,

- Seyahat medyasının tur operatörleri ve üyelerini davet etmek ve ağırlamak,

- Bölgesel bir seyahat birliği kurmak (İzmir, 1994),

- KEİ bölgesi için bölgesel bir turizm fuarı kurmak (Romanya-Bükreş-1997),

Turkish Studies - Economics, Finance, Politics

Volume 14 Issue 2, 2019 
- KEİ bölgesinin potansiyel turizm çeşitliliği üzerine ortak ürün alternatifleri, deneyim ya da kültür turları (ülke turlarıyla uyum sağlayan ve yarı merkezi şehir turları), sanat ve kültür turları, güzel sanatlar festival turlar, inanç veya dini turlar ve eko turlar gibi özel ilgi turların düzenlenmesi (Sofia,1998),

- KEİ ülkelerinde turizm olanaklarını ortaya çıkarmak, tanıtımını yapmak amacıyla bir broşür yayınlanması fikrinin orta çıkmasıdır.

\subsection{KEİ Bölgesine Yönelik Turizm Teşvikleri}

KEİ, Karadeniz bölgesinde turizm faaliyetlerinin artırılması, geliştirmesi için bir takım teşvikler sağlamaktadır. Bu teşvikler ilk toplantılarda ülkelerin kendi mevcut yasalarının incelenmesi şeklinde öne çıkmış daha sonraki süreçte, ortak hedefler doğrultusunda bu yasaların düzenlenmesi, geliştirilmesi/yenilenmesi gündeme gelmiştir. Bu süreç aşağıda yer almaktadır:

- KEİ üye devletlerinin, yabancı yatırımları çekmek için teşvik konusunda mevcut yasal çerçevelerine iliş̧in ön bilgi talebi istenmiştir.

- Yatırımların Teşvik Edilmesi ve Korunması üzerine Uzman Çalışma Grubu ile bu konuda etkileşimin kolaylaştırılması için talimat verilmiştir.

- Çalışma Grubu KEİ Koordinasyon merkezine yabancı teşvikler ile ilgili turizm alanında yabancı yatırımların teşvik tedbirlerine ilişkin katılımcı devletlerin kanunları çerçevesinde bilgi derlemek amaciyla Türkiye Devlet İstatistik Enstitüsü bünyesinde istatistiki veri ve ekonomik bilgi değişimi için talimat verdi ve Uluslararası Daimi Sekretaryası yoluyla katılımcı devlet arasında bunun dönüşümünü sağlamak, yatırımlarla ilgili verileri derlemek ve güncel formda sunmak için çalışmalar başlatılmıştır.

- Uluslararası finansal kuruluşların mali desteği ile başlatılan turizm altyapı ve üstyapı projelerinin incelenmesi.

- Çalışma Grubu, özellikle uluslararası kuruluşlarla muhtemel bir yardım için temas başlatmak hususunda KEİ Uluslararası Daimi Sekretaryasına talimat verildi (İzmir, 1994).

- KEİ bölgesinde uluslararası mali ve ekonomik kurumlardan bazı turizm projeleri için olası yardımların belirlenmesi amacıyla fikir alışverişinde bulunuldu ( Avrupa Komisyonu, WTO, gibi) (Romanya-Bükreş-1997).

- Hem Karadeniz bölgesi içinde hem de dışındaki turistlerin, turizm işletmelerini ve hizmetlerini geliştirmek ve ilerletmek amacıyla katılımcı devletlerde turizm altyapısı ile ilgili bir dizi somut projeler hakkında bilgi alışverişinde bulunuldu (Sofia, 1998).

- Çalışma Grubu KEİ üye devletlerde özellikle turizm yatırımlarının rolünü artırmak için turizm endüstrisine yatırımları çekmenin gerekleri düşünüldü, tartışıldı.

- Bu bağlamda katılımcılar, İstanbul'da yapılacak 26-27 Kasım 1998 Tourism Investment Exchange ilgili Türkiye Turizm Yatırımları Birliğinin bilgilerini sıcak karşıladı (Sofia, 1998).

- Ulusal delegasyonlar ulusal ve bölgesel düzeyde turizmin gelişmesini teşvik etmek amacıyla sunulan teşviklerin yanı sıra kendi ülkelerinde turizm sektöründe meydana gelen son gelişmeler ile bilgi verildi (Bükreş, 2006).

- Karadeniz bölgesinde turizmi teşvik canlandırma için DTÖ, AB ve diğer uluslararası organizasyonların veya turizmle ilgili kuruluşların deneyim ve bilgi birikimlerinden yararlanmak adına yakın ilişkilerin devam ettirilmesinin önemi vurgulanmıştır (Atina, 2010). 


\subsection{KEİ Bölgesine Yönelik Özel Sektörün Teşviki}

KEİ üye ülkeleri uygulamalarının arasında turizm teşvikleri yanında özel sektör teşvikleri de bulunmaktadır. $\mathrm{Bu}$ teşvikler de dolaylı olarak bölge turizminin gelişimine katkı sağlamaktadır. Aşağıda bu kapsamda yer alan teşvikler yer almaktadır:

- KEİ toplantılarının bazılarında özel sektör temsilcilerini davet ederek özel sektör ile görüş ve öneri alışverişinde bulunmaktadır. Bu bakış açısıyla KEİ İş Konseyi faaliyetlerinin öneminin altını çizmiştir (Romanya-Bükreş-1997).

- Çalışma Grubu hükümet yetkilileri ve özel sektör arasında iletişimin daha da geliştirilmesine karar verdi ve bu bağlamda KEİ çatısı altında ulusal tur operatörleri ile işbirliğinin ihtimalleri üzerine dikkat çekildi (Belgrad,2007).

\subsection{KEİ Bölgesine Yönelik Ĕgitim}

KEİ turizmin bölgede geliştirilmesi kapsamında eğitime de önemli bir yer vermektedir. Turizme yönelik eğitimlerinin sağlanabilmesi için dönemsel olarak programlar oluşturmaktadırlar. İstanbul Boğaziçi Ǘniversitesi içinde bulunan UNWTO'ya bağlı Turizm Eğitim Merkezi tarafından önerilen turizm alanında eğitim için KEİ PERMİS somut önerilerini sunma çağrısını yinelemiştir. Aşağıda yıllar itibari ili turizm eğitimlerine yönelik çalışmalar yer almaktadır:

- Çalışma grubu katılımcı devletler için turizm alanında eğitim programlarının geliştirilmesi için daha ileri adımlar atılmasına dikkat çekerek, Antalya'da 1996 yılında düzenlenen otel ikram hizmetleri ve turizm ile ilgili ilk workshop ile ilgili ulaşılan deneyim paylaşıldı (Bükreş-1997).

- Katılımcılar, özellikle okullarda ve seyahat acentelerince verilen stajlarda KEİ bölgesinde eğitimli personel yetiştirmek amacıyla üye devletler arasında değişim programının gerekliliğini dile getirdi.

- Aile otelleri, catering, kırsal, tarım ve doğa turizmi gibi yeni alanlarda istihdam sağlamak için stajlar ve seminerler düzenlenmesi kararına vardı.

- Çalışma grubu Türkiye'den gelen, KEİ bölgesinde turizm eğitimi ile ilgili teklifi not aldı. $\mathrm{Bu}$ konuda Türkiye gönüllülüğünü ortaya koyarak eğitim programları gerçekleştirmek, eğitimcilerin eğitimi, iş başında eğitim, sosyal yetenek seminerleri, teknik dil öğrenim kursları ile ilgili çeşitli seminerler, kurslar organize etme düşüncesi öne sürüldü

- KEİ bölgesinin potansiyel çeşitliliği üzerine ortak ürün alternatifleri, deneyim ya da kültür turları (ülke turlarıyla uyum sağlayan ve yarı merkezi şehir turları), sanat ve kültür turları, güzel sanatlar festival turlar, inanç veya dini turlar ve eko turlar gibi özel ilgi turları (Sofia, 1998).

- Turizm bakanları ve heyet başkanları Boğaziçi üniversitesi DTÖ eğitim ve öğrenim merkezi temsilcisinin Anlayış Memorandumu girişimi sunumu ile ilgili notlar aldı. Bu hususta, KEI Bütünleşmiş Destinasyon Gelişimi konulu İstanbul'da bir araştırma toplantısı yapılması teklifinde bulunuldu (Tirana, 2002).

- Türkiye Cumhuriyeti heyet başkanı Aralık 2003 Pazarlama ve tutundurma stratejileri üzerine bir kurs organizasyonunun düzenlenebileceğini bildirdi.

- Helenik Cumhuriyeti Konaklama sektöründe İnsan Kaynakları Yönetiminde Eğiticinin Eğitimi” adı altında bir seminer düzenleneceğini bildirdi (Thessaloniki, 2003).

- Çalışma gurubu 06-17 Kasım 2005 de düzenlenen KEİ Avrupa'ya daha yaklaştırmak, Eğiticilerin Eğitimi konulu seminerlerin sonuçlarını memnuniyetle bildirdi. Katılımcılar, Çalışma Grubunun ülke koordinatörü sıfatıyla Yunanistan tarafından üstlenilen bu faaliyeti yararlı bir girişim 
olarak değerlendirdi ve yakın gelecekte diğer üye ülkelerin de bu benzer faaliyetlerde bulunmalarını dile getirdi (Bükreş, 2006).

- Uluslararası Turizm Fuarı "IMTOURMARKET" çerçevesinde turizm alanında verilen konferansa ilişkin bilgiler paylaşıldı.

- Gelendzhik'te Yıllık Konferans çerçevesi içinde turizm alanında eğitim üzerine yuvarlak masa toplantıları düzenlendi (İstanbul, 2009).

- Daha yüksek kalitede hizmet anlayışı içerisinde, turizm sektöründe istihdam edilecek personel için eğitim ve personel değişim programlarının organize edilmesi ve turizm eğitimi veren kuruluşlar arasında sinerji yaratmak hedefi belirlendi (Atina, 2010).

- UNWTO’nun Boğaziçi Üniversitesi UNWTO'ya bağlı Turizm Eğitim Merkezi'nde gerçekleşmek üzere turizm profesyonellerinin eğitim ve öğretimi konusu dikkate alınmıştır (Burgaz, 2017).

- UNWTO ile işbirliği içinde "Çinli turistlerin KEİ Bölgesine daha etkin biçimde nasıl çekileceği" konusunda bir Seminer organizasyonu planlaması gündeminde yer almıştır (Burgaz, 2017). Aynı konuya ilişkin 2018 yılı gündeminde ise "Çinli ve Hintli Turistler" ifadesi kullanılmıştır (Varna, 2018).

- UNWTO’nun Boğaziçi Üniversitesi'nin İstanbul'da yer alan UNWTO’ya bağlı Turizm Eğitim Merkezi tarafından önerilen turizm alanında eğitim için KEİ PERMİS somut önerilerini sunma çağrısını yinelemiştir (Varna, 2018).

\subsection{KEİ Bölgesine Yönelik Diğer Çalışmalar}

KEİ Bölgesine Yönelik Turizm Planlaması kapsamında pazar hedef ve stratejilerine dayalı KEİ bölgesinde uzun veya orta dönemli bir program hazırlama üzerinde hem fikir olmuşlardır (RomanyaBükreş-1997).

KEİ Bölgesine Yönelik Tesislerin İyileştirilmesi kapsamında katılımcı devletlerin turizm altyapısı ile ilgili bir dizi somut projeler ilgili devletler tarafından sunulmuş ve Çalışma Grubu hem Karadeniz bölgesi içinde hem de dışındaki turistler için turizm tesis ve hizmetlerinin iyileştirilmesi ve geliştirilmesi yönünde ulusal düzeyde yapılan çalışmalar ile ilgili gerekli notlar alınmıştır (Bükreş1997).

Bölgedeki kültürel dokunun benzeşmesi ve daha önce kapalı siyasi rejim sebebiyle bölge ülkelerine yönelik oluşan merak faktörleriyle bu yönde bir turistik faaliyeti hızlandırabilmektedir. Bu açıdan değerlendirdiğimizde başlangıçta ticari faaliyetler ile başlayan karşılıklı ziyaretçi gidiş-gelişleri geniş kapsamlı turistik faaliyetler yönünde gelişmiştir. Yukarıdaki tabloları incelediğimizde ise yıllar itibariyle ziyaretçi sayısının artmış olması bu yönde gelişimi doğrulamaktadır.

Turizm, Karadeniz Ekonomik İşbirliği Örgütü üyeleri arasında geleceğe yönelik işbirliği konuları arasında yer bulmaktadır. Bu konuda örgüt üyesi kamu kurum ve kuruluşlarının yanında özel sektörün de bu yönde ve destekleyici nitelikte olması gerekmektedir. Bu işbirliği çerçevesinde sadece altyapı imkanlarının değil üst yapıya ilişkin de önemli çalışmaların yapılması gerekmektedir. $\mathrm{Bu}$ çerçevede Turizm Bakanlı̆̆ üye ülke katılımcılarına kurslar ve eğitim programları düzenlemiş̧tir (http://www.mfa.gov.tr). Özellikle eğitim amacı taşıyan programlar nicelik ve nitelik açısından önemli gelişmelerin sağlanmasına katkıda bulunmaktadır.

Karadeniz'e komşu ülkeler arasında ekonomik faaliyetlerin hızlı bir şekilde gelişmesinde KEİ son derece etkilidir. Bölge ülkelerinin coğrafi açıdan yakınlığı, ekonomik ve karşılıklı sosyal ilişkiler işbirliğinin oluşumunda ve ilişkilerin geliştirilmesinde önemli olmaktadır. Üye ülkeler arasındaki kültürel yakınlıklar ise bölgede ekonomik, kültürel ve sosyal gelişimin sağlanmasına katkıda 
bulunmaktadır. Karadeniz Bölgesi ülkeleri tarım, enerji, doğal kaynaklar, doğal fiziksel özellikler ve kültürel değerler bakımından son derece zengin kaynaklara sahiptir. Özellikle bölgenin doğal fiziksel özellikleri ve kültürel değerleri turizm sektörünün gelişmesine imkan vermektedir. Turizmin bölge ülkelerinde gelişimi bölgesel kalkınmanın sağlanmasında önemli olmaktadır.

\section{Sonuç ve Değerlendirme}

Ekonomik işbirlikleri ekonomik, ticari, kültürel, siyasi ilişkileri geliştirerek, ülkelerinin kalkınmalarına katkıda bulunabilmek amacı taşımaktadırlar. Aynı zamanda çevre korunması ve iyileştirilmesinin sağlanmasında ve kültürel değerlerin muhafazasında da önemli katk1 sağlamaktadırlar. Bu doğrultuda oluşturulacak işbirlikleri her aşamada önemli katkı sağlamasının yanında turizm gelirleri, turist sayıları ve ortalama harcamaların arttırılması yönünde de önemli olacaktır. Sürdürülebilir turizmin sağlanmasında bölgenin doğal çevre dokusunun ve kültürel değerlerin korunması son derece önemlidir. Ülkelerarası işbirlikleri bölgesel değerlerin korunması ve iyileştirilmesine de katkı sağlamaktadır. Bu kapsamda karşılıklı olarak ortak yapılan planlamalar ve uygulamalar sürdürülebilir kalkınma ve sürdürülebilir turizmin sağlanması açısından önemlidir. $\mathrm{Bu}$ çalışmada inceleme alanımız içinde olan KEİ ise bu konuda önemli bir hareket olmaktadır. KEİ, bölgesel kalkınmanın sağlanması ve ticari ilişkilerin geliştirilmesi açısından son derece önemlidir.

KEİ pazarı, coğrafi olarak Avrupa, Orta Asya ve Orta Doğu bölgelerine kolaylıkla ulaşabilir ve oradaki pazarlarda söz sahibi olabilir konumdadır. Ayrıca Karadeniz, yeryüzündeki dördüncü büyük iç su olduğundan dolayı hem deniz taşımacılığı anlamında iktisadi imkanlara sahiptir hem de deniz turizmi açısından önemli bir zenginlik kaynağına sahiptir. Bu açıdan ekonomik ve ticari açıdan üye devletlerin işbirliğini arttırmak amacıyla sektörel işbirliği alanları belirlenmiş ve bu alanlar içinde turizm de yer almaktadır. KEİ bölgesinde turizmin geliştirilebilmesi için yapılacak olan çalışmalar arasinda;

- Önde gelen turizm destinasyonlarından biri olarak KEİ bölgesini teşvik etmek,

- Vize işlemlerinin kolaylaştırılması başta olmak üzere, turizm alanında üye devletlerin işbirliğinin güçlendirilmesi,

- Sürdürülebilir turizmin gelişmesini sağlamak,

- KEİ bölgesinde yeni turizm paketlerini teşvik etmek,

- KEİ üyeleriyle diğer devletlerarasında ortak pazarlama çalışmaları yapmak,

- Üye devletlerin turizm profesyonelleri, seyahat acenteleri ve dernekleri arasında bir ağ kurmak,

- Denizcilik, kış sporları, sağlık, SPA, Wellness ve iş turizmi alanında ortak projeleri geliştirmek,

- Karadeniz bölgesinde, kültür turizmi/kültür yolları projelerini teşvik etmek,

- KEİ üyesi devletlerdeki öğrencilerin staj olanaklarını artırmak ve turizm ve otelcilik sektörlerinde kariyerlerine devam etmek isteyen mezunlara yönelik bir web portalı oluşturma, bulunmaktadir.

Karadeniz'e komşu ülkeler arasında ekonomik faaliyetlerin hızlı bir şekilde gelişmesinde KEİ son derece etkilidir. Karadeniz Bölgesi ülkeleri tarım, enerji, doğal kaynaklar, doğal fiziksel özellikler ve kültürel değerler bakımından son derece zengin kaynaklara sahiptir. Bölge ülkeleri arasında işbirliğini geliştirmek için belirlenen alanlar içinde turizmin bölgesel gelişmeye katkıları son derece önemlidir. Özellikle bölgenin doğal fiziksel özellikleri ve kültürel değerleri turizm sektörünün gelişmesine imkan vermektedir. Turizmin bölge ülkelerinde gelişimi bölgesel kalkınmanın 
sağlanmasında önemli olmaktadır. Özellikle turizmin çeşitlendirilmesi, çevrenin korunması ve sürdürülebilir turizminin benimsenmesi bölgede çevre ve kültürel değerlerin korunması ve turizmin çeşitlendirilmesine imkan vermektedir. Ayrıca, turizm eğitiminin bölgede etkin şekilde sağlanması ve tesislerde hizmet kalitesinin arttırılması nitelikli işgücünün ve nitelikli tesislerin gelişmesini sağlamaktadır. Aynı zamanda turizm planlamasının yapılması, özel sektörün turistik yatırımlar için teşvik edilmesi ve bölge ülkelerinin ortak çalışma birliktelikleri bölge ekonomisini güçlendirebilmektedir. KEİ üye ülkelerde tanıtım çalışmalarına öncelik verilmesi ve vize kolaylıkları bölge ülkelerine yönelik turistik talebin artışını sağlayacaktır. Bu gelişime katkı sağlayacak çalışmalar üye ülkeler arasındaki ortak çalışmalar ve işbirlikleri ile ele alınmıştır. Bu konudaki çalışma grupları ortak hareket etme konusunda duyarlı bir tavır izlemişledir. Bölgesel gelişimin sağlanmasında son derece önemli olan çalışmaların ve protokollerin geliştirilmesi zorunluluktur.

\section{KAYNAKÇA}

Ergüven, M.H. (2015). Gastronomy And Wine Tourısm As A Varıety Of Special Interest Tourısm: Thracian Vineyard Route, Turkish Studies International Periodical for the Languages, Literature and History of Turkish or Turkic, Volume 10/10, s. 449-464. DOI Number: http://dx.doi.org/10.7827/TurkishStudies.8709.

Gürlesel, C.F., Demir, M.F. (2002). Dünyada Çok Taraflı Denge ve Türkiye İçin Yakın Gelecek, İTO Yayın No:2002-20, Mega Ajans, İstanbul.

http://www.eecon.info/papers/661.pdf

İstanbullu Dinçer, F., Dinçer, M.Z., Gedik, S. (2015). Uluslararası İktisadi Örgütlerin Türk Turizm Endüstrisinin Gelişimindeki Rolleri, Uluslararası Sosyal Araştırmalar Dergisi, Cilt: 8 Sayı: 37, s. 1107-1113.

Karadeniz Ekonomik birliği Parlamenter Asamblesi (PABSEC), http://www.pabsec.org/

Kiraz, S. (2018). Türk Dış Politikasında Çok Yönlülük Denemeleri Bağlamında Karadeniz İşbirliği Örgütü Ve D-8'in Karşılaştırmalı Olarak Analizi, Turkish Studies Economics, Finance And Politics, Volume 13/14, s.125-140. DOI Number: http://dx.doi.org/10.7827/TurkishStudies.13752.

Koca, N., Yazıc1, H., Ekiz, E. (2018). Afyonkarahisar'da Keçecilik ve Keçeciliğin Kültürel Turizm Açısından Değerlendirilmesi, Turkish Studies Social Sciences, Volume 13/18, s. 939-957. DOI Number: http://dx.doi.org/10.7827/TurkishStudies.13951.

KOSGEB-Küçük ve Orta Ölçekli İşletmeleri Geliştirme ve Destekleme Dairesi Bakanlığı, http://www.kosgeb.gov.tr/

T.C. Dışilişkiler Bakanlığı, http://www.mfa.gov.tr/karadeniz-ekonomik-isbirlici-_kei_---orgutunun dunu_-bugunu-ve-gelececi.tr.mfa

T.C. Ticaret Bakanlığı, AB ve Dış İlişkiler Genel Müdürlüğü, https://ab.ticaret.gov.tr/uluslararasi orgutler/karadeniz-ekonomik-isbirligi-orgutu.

T.C. Turizm ve Kültür Bakanlığı, Avrupa Birliği ve Dış İlişkiler Dairesi Başkanlığı, http://disiliskiler.kulturturizm.gov.tr/TR-22155/karadeniz-ekonomik-isbirligi-orgutu-kei.html.

The Black Sea Economic Cooperation (BSEC), http://www.bsecorganization.org/Pages/homepage.aspx

Uray, R. (2008). Ekonomik Büyüme Verimlilik ve Rekabet, 1.Baskı, Kumsaati Yay.Dăg.Ltd.Şti., İstanbul. 